Pneumonia Risk Score: Validity in a French Stroke Unit.", J Stroke Cerebrovasc Dis, 26(1), pp:225-229.

7. Smith C.J., Kishore A.K., Vail A. et al (2015), "Diagnosis of Stroke-Associated Pneumonia", Stroke, 46(8), p. 2335-2340.

8. Papavasileiou $V$, Milionis $H$, Smith CJ et al
(2015), "External Validation of the Prestroke Independence, Sex, Age, National Institutes of Health Stroke Scale (ISAN) Score for Predicting Stroke-Associated Pneumonia in the Athens Stroke Registry.", J Stroke Cerebrovasc Dis, 24(11), pp:2619-2624.

\title{
MỨC Độ SÃ̃N SÀNG CHI TRẢ CHO SÀNG LỌC TRƯỚC SINH HộI CHỨNG DOWN TẠI BỆNH VIỆN PHỤ SẢN HÀ NộI NĂM 2020 \\ Nguyễn Duy Ánh*
}

\section{TÓM TẮT}

Mục tiêu: Nghiên cứu nhằm xác định tỷ lệ và mức sẵn sàng chi trả của phụ nữ mang thai cho việc sàng lọc trước sinh hội chứng Down tại bệnh viện Phụ sản Hà Nô̂i năm 2020. Phương pháp: Sử dụng phương pháp lượng giá ngẫu nhiên phụ thuộc với thiết kế cậu hỏi có - không nhằm ước tính tỷ lệ và mức độ sẵn sàng chi trả đối với việc sàng lọc trước sinh hội chứng Down trên 223 phụ nữ mang thai được lựa chọn ngẫu nhiên từ danh sách người bệnh đến khám tại Trung tâm Chẩn đoán trước sinh và sàng lọc sơ sinh Bệnh viện Phụ sản Hà Nội từtháng 3 đến tháng 6 năm 2020. Kết quả và kết luận: Kết quả cho thây $95 \%$ phụ nữ mang thai sẵn sàng chi trả cho biện pháp sàng lọc kết hợp, mức giá trung bình để thai phư sẵn sàng chi trả là 1.905 .010 đồng. Tuy nhiên, chỉ có $65 \%$ thai phụ sẵn sàng chi trả cho xét nghiệm tiền sản không xâm lấn, mức giá trung bình để thai phụ sẵn sàng chi trả là 9.097.230đ̛̂̀ng.

Tư khoá: Sẵn sàng chi trả, sàng loc trước sinh, sàng lọc kết hợp, xét nghiệm tiền sản không xâm lấn, bệnh viện Phụ sản Hà Nội

\section{SUMMARY}

\section{WILLINGNESS TO PAY FOR DOWN} SYNDROME PRENATAL SCREENING OF PREGNANT WOMEN AT HANOI OBSTETRICS

AND GYNECOLOGY HOSPITAL, 2020

Objective: To determine the rate and willingness to pay of pregnant women for Down syndrome prenatal screening at Hanoi Obstetrics and Gynecology Hospital in 2020. Method: Employing contigent valuation method with double-bounded question design to estimate willingness to pay for prenatal screening for Down syndrome with 223 pregnant women randomly selected from the list of patients visiting the Center for Prenatal Diagnosis and Newborn Screening at Hanoi Obstetrics and Gynecology Hospital from March to June, 2020. Results and conclusions: The results showed that $95 \%$ of

*Bệnh viện Phụ sản Hà Nội

Chịu trách nhiệm chính: Nguyễn Duy Ánh

Email: bsanhbnhn@yahoo.com

Ngày nhận bài: 8.4.2021

Ngày phản biên khoa học: 28.5.2021

Ngày duyệt bài: 9.6.2021 pregnant women were willing to pay for combined screening, the average price for which pregnant women were willing to pay was VND 1,905,010. However, only $65 \%$ of pregnant women were willing to pay for a non-invasive prenatal test, the average price for a pregnant woman willing to pay was VND $9,097,230$.

Keywords: willingness to pay, prenatal screening, combined screening, non-invasive prenatal test, Hanoi Obstetrics and Gynecology Hospital

\section{I. ĐĂTT VẤN ĐỀ}

Hội chứng (HC) Down là một trong những bất thường nhiễm sắc thể dễ bi bỏ sót trên siêu âm thai nhi và nhiều nghiên cứu trên thế giới cho thấy nguy cơ thai mắc HC Down tăng theo tuổi mẹ. Theo Tổ chức y tế thế giới (WHO), tỷ lệ mắc HC Down là 1:800 đến 1:1000 trẻ sinh sống. Theo nghiên cứu của Lê Thanh Thúy thực hiện tại Bệnh viện Phụ sản Hà Nội năm 2014, tỷ lệ thai nhi mắc HC Down chiếm 38\% những trường hợp có bất thường nhiễm sắc thể. Một trong những giải pháp để tăng chất lượng dân số, giảm gánh nặng bệnh tật cho gia đình là thực hiện các biện pháp sàng lọc trước sinh. Việc thực hiện các biện pháp sàng lọc sẽ giúp phụ nữ mang thai (PNMT) biết được nguy cơ thai nhi có mắc HC Down hay không, đối với các trường hợp có nguy cơ cao sẽ được tư vấn và chỉ định chọc ối hoặc sinh thiết gai rau để chẩn đoán chính xác tình trạng bất thường nhiễm sắc thể của thai nhi. Tuy nhiên tỷ lệ sảy thai do chọc ối khoảng 1-2\%. Sàng lọc kết hợp trong 3 tháng đâu mang thai (FTS) có tỷ lệ dương tính giả $>5 \%$ và độ chính xác $80-85 \%$. Từ năm 1997, các nhà nghiên cứu trên thế giới đã tìm ra biện pháp xét nghiệm tiền sản không xâm lấn (NIPT) sử dụng ADN tự do của thai nhi có trong máu mẹ để sàng lọc HC Down, xét nghiệm này có độ chính xác cao (>95\%) và tỷ lệ dương tính giả thấp (<1\%).

Khái niệm sẵn sàng chi trả đề cập đến giá trị kinh tế của một người hay một gia đình sẵn sàng chi trả cho một dịch vụ nào đó trong điêu kiện kinh tế cho phép. Sự sẵn sàng chi trả ở đây thực 
chất là số tiền lớn nhất mà PNMT hoăc gia đình sẵn sàng bỏ ra để được hưởng lợi ích từ các biện pháp sàng lọc trước sinh. Thông tin về tỷ lệ và mức sẵn sàng chi trả của PNMT đối với 2 biện pháp sàng lọc trước sinh HC Down bằng FTS và NIPT là hữu ích cho các nhà hoạch định chính sách, quản lý bệnh viện trong việc áp dụng biện pháp sàng lọc nào để phù hợp với điêu kiện kinh tế của PNMT. Tại Việt Nam đã có nhiều nghiên cứu về tình trạng dị tật bẩm sinh, tuy nhiên ít nghiên cứu về khía cạnh kinh tế, đặc biệt là về tỷ lệ và mức sẵn sàng chi trả của PNMT về các biện pháp sàng lọc trước sinh. Từ các lý do đó, nghiên cứu này được thực hiện với mục tiêu:Xác định tỷ lệ và mức sẵn sàng chi trả cho biện pháp sàng lọc trước sinh hội chứng Down bằng sàng lọc kết hợp trong 3 tháng đâu mang thai và xét nghiệm tiền sản không xâm lấn.

\section{II. ĐỐI TƯợNG VÀ PHƯƠNG PHÁP NGHIÊN CỨU}

Đia điểm nghiên cứu: Nghiên cứu được tiến hành tại Bệnh viện Phụ sản Hà Nội trong khoảng thời gian từ tháng 3 đến tháng 6 năm 2020.

Đối tượng nghiên cứu: phụ nữ mang thai đến khám tại Trung tâm chẩn đoán trước sinh và sàng lọc sơ sinh Bệnh viện Phụ sản Hà Nội

Thiết kế nghiên cứu: nghiên cứu điêuu tra mô tả cắt ngang

Cỡ mẫu và chọn mẫu: Áp dụng cách tính cõ mẫu trung bình quân thể. 223 PNMT được lựa chọn ngẫu nhiên từ danh sách người bệnh đến khám tại Trung tâm Chẩn đoán trước sinh và sàng lọc sơ sinh Bệnh viện Phụ sản Hà Nội.

Kỹ thuât và công cư thu thập số îệu: Kỹ thuật phỏng vấn PNMT sử dụng phương pháp định giá ngẫu nhiên phụ thuộc (Contingent Valuation Method: CVM). CVM là kỹ thuật điêu tra kinh tế học dựa vào các câu hỏi trực tiếp các cá nhân về sự sẵn sàng chi trả cho một loại mặt hàng, dịch vụ nào đó $(1,2)$.

Trong nghiên cứu này, chúng tôi áp dụng phương pháp CVM với 10 mức giá được đưa ra để hỏi PNMT về sự sẵn sàng chi trả của họ cho biện pháp sàng lọc trước sinh hội chứng Down (các mức giá được đưa ra tăng/giảm 10\% so với mức giá hiện tại đang áp dụng tại Bệnh viện) và khi PNMT có kết quả nguy cơ cao sau khi làm NIPT sẽ được miễn phí chi phí chọc ối.

5 mức giá tăng của FTS là 1.540.000đồng; 1.695 .000 đồng; 1.850 .000 đồng;2.000.000 đồng và 2.155 .000 đồng

5 mức giá giảm của FTS là 1.370 .000 đồng;1.215.000 đồng;1.060.000 đồng;908.000 đồng và 755.000 đồng
5 mức giá tăng của NIPT là 8.000.000 đồng; 8.800.000 đồng; 9.600 .000 đồng; 10.400 .000 đồng và 11.200 .000 đồng

5 mức giá giảm của NIPT là 7.200.000 đồng; 6.400.000 đồng; 5.600.000 đồng; 4.800 .000 đồng; 4.000.000 đồng

Bộ công cụ: Bộ câu hỏi điều tra được thiết kế bởi nhóm nghiên cứu sau khi thảo luận với PNMT và có tham khảo các bô câu hỏi sử dụng trong nghiên cứu CVM trên thế giới và ở Việt Nam (2-6).

Quản lý, xử lý và phân tích số liệu: Số liệu sau khi được thu thập, làm sạch và nhập vào máy tính bằng phân mềm Epidata 3.1 , số liệu thống kê được phân tích bằng phân mềm thống kê SPSS 16.0.

\section{KẾT QUẢ NGHIÊN CứU}

Bảng 1. Thông tîn chung của đôî tượng nghiên cứu

\begin{tabular}{|c|c|c|c|}
\hline \multicolumn{2}{|c|}{ Thông tin chung } & $\begin{array}{c}\text { Số } \\
\text { lượng }\end{array}$ & $\begin{array}{c}\text { Tỷ lệ } \\
(\mathbf{0})\end{array}$ \\
\hline \multirow{2}{*}{ Tuổi } & $<35$ tuối & 184 & 82,7 \\
\cline { 2 - 4 } & $>35$ tuối & 39 & 17,3 \\
\hline \multirow{3}{*}{$\begin{array}{c}\text { Nghề } \\
\text { nghiêp }\end{array}$} & Cán bộ công chức & 87 & 39 \\
\cline { 2 - 4 } & Công nhân & 11 & 5 \\
\cline { 2 - 4 } & Nông dân & 0 & 0 \\
\cline { 2 - 4 } & Các ngành khác & 125 & 56 \\
\hline \multirow{2}{*}{$\begin{array}{c}\text { Trình độ } \\
\text { học vấn }\end{array}$} & Cao đằng, đại học & 132 & 59 \\
\cline { 2 - 4 } & Trung học phố thồng & 91 & 41 \\
\hline \multirow{3}{*}{ Nơi ở } & Nội thành Hà Nội & 89 & 39,8 \\
\cline { 2 - 4 } & Ngoại thành Hà Nội & 54 & 24,1 \\
\cline { 2 - 4 } & Địa phương khác & 80 & 36,1 \\
\hline
\end{tabular}

Trong 223 PNMT được điêuu tra, có 184 trường hợp PNMT dưới 35 tuổi, chiếm tỷ lệ $82,7 \%$. Trình độ học vấn là cao đẳng và đại học chiếm tỷ lệ $59 \%$, còn lại là trình độ dưới phổ thông. Về nghề nghiệp của các đối tượng nghiên cứu, chiếm phân lớn là kinh doanh, nghề tự do (56\%), cán bộ công chức chiếm tỷ lệ $39 \%$, còn lại là công nhấn (5\%), không có trường hợp nào là nông dân. Kết quả phỏng vấn cho thâyy thu nhập trung bình hang tháng của đối tượng nghiên cưuu là 9.368.131 đồng.

Bảng 2. Mức chi trả trung bình cho sàng loc trước sinh hội chứng Down và thu nhập binh quân của PNMT

\begin{tabular}{|c|c|c|}
\hline & FTS & NIPT \\
\hline Trung bình WTP & 1.905 .010 & 9.097 .230 \\
\hline Trung vị WTP & 1.850 .000 & 8.800 .000 \\
\hline $\begin{array}{c}\text { Trung bình thu nhập } \\
\text { tháng (đồng) }\end{array}$ & \multicolumn{2}{|c|}{9.368 .131} \\
\hline $\begin{array}{c}\text { Trung vị thu nhập } \\
\text { tháng (đồng) }\end{array}$ & \multicolumn{2}{|c|}{8.500 .000} \\
\hline
\end{tabular}




\begin{tabular}{|c|c|c|}
\hline $\begin{array}{c}\text { Trung bình thu nhập } \\
\text { năm (đồng) }\end{array}$ & \multicolumn{2}{|c|}{112.417 .582} \\
\hline $\begin{array}{c}\text { Trung vị thu nhập } \\
\text { năm (đồng) }\end{array}$ & \multicolumn{2}{|c|}{102.000 .000} \\
\hline $\begin{array}{c}\text { \%WTP/thu nhập } \\
\text { (trung vị) }\end{array}$ & $1,8 \%$ & $8,6 \%$ \\
\hline
\end{tabular}

Để xác định chính xác PNMT sằn sàng chi trả cho các biện pháp sàng lọc trước sinh HC Down với mức giá là bao nhiêu, nhóm nghiên cứu áp dụng mô hình hồi quy phân tích khoảng (Interval Regresstion Model) với hai mức giá cao nhất và thấp nhất PNMT sã̃n sàng chi trả, sau đó tính trung bình mức giá mà PNMT sẵn sàng chi trả cho các biện pháp sàng lọc trước sinh HC Down. Cho đến nay vẫn có hai cách tính trung bình mức sẵn sàng chi trả của PNMT là lấy trung bình hoặc trung vị của hàm sẵn sàng chi trả (WTP), tuy nhiên, trung vị của WTP được nhiều người chấp nhận hơn là trung bình bởi số liệu liên quan đến kinh tế thường không phân bố chuẩn và kết quả lấy trung vị thường chính xác hơn, thực tế hơn. Bảng 2 cho thấy trung vị mức trung bình chung của PNMT sẵn sàng bỏ ra để làm sàng lọc trước sinh HC Down là 1.850.000 đồng đối với FTS, chiếm $1,8 \%$ tổng thu nhập hàng năm và 8.800 .000 đồng đối với NIPT, chiếm 8,6\% tổng thu nhập hàng năm của PNMT.

Kết quả phỏng vấn PNMT cũng cho thấy, khi mức giá của FTS cao hơn mức sẳn sàng chi trả của PNMT, phần lớn PNMT lựa chọn phương án thay thể bằng các biện pháp sàng lọc rẻ hơn (chỉ siêu âm đo khoảng sáng sau gáy, hoặc chỉ làm xét nghiệm sinh hóa máu me Double test). Khi mức giá của NIPT cao hơn mức sẵn sàng chi trả, PNMT sẽ lựa chọn các biện pháp khác rẻ hơn (ví dụ: sàng lọc kết hợp trong 3 tháng đầu, sàng lọc 3 tháng giữa, chọc ối,...). Chỉ có $0,6 \%$ PNMT trả lời khônng làm sàng lọc nếu mức giá vượt quá mức sẵn sàng chi trả, $15 \%$ PNMT lựa chọn cơ sở khám chữa bệnh khác để tiến hành làm sàng lọc.

\section{BÀN LUÂ̂N VÀ KẾT LUẬN}

Kết quả nghiên cứu của chúng tôi cũng tương đồng với nghiên cứu của E.Verweij và cs thực hiện năm 2013 (7), nghiên cứu của Verweij cho kết quả tỷ lê PNMT sẵn sàng chi trả để làm sàng lọc kết hợp là $81 \%$, tuy nhiên khi có NIPT thì tỷ lệ PNMT chấp nhận làm NIPT là $57 \%$. Kết quả nghiên cứu cũng phù hợp với tình hình thực tế tại Bệnh viên Phụ sản Hà Nội trong những năm gần đây, khi đời sống và nhận thức của PNMT cao hơn, họ sẽ quan tâm và đầu tư nhiều vào lĩnh vực chắm sóc sức khỏe, sàng lọc trước sinh và chẩn đoán sơ sinh.

Đây là một trong những nghiên cứu đầu tiên tại Việt Nam nghiên cứu mức sẵn sàng chi trả của PNMT đối với sàng lọc trước sinh. Kết quả nghiên cứu của chúng tôi cho thấy có $95 \%$ PNMT sẵn sàng làm sàng lọc trước sinh hội chứng Down bằng sàng lọc kết hợp (FTS) với mức sẵn sàng chi trả trung bình là 1.905.010 đồng và $65 \%$ PNMT sẵn sàng chi trả 9.097.230đồng cho xét nghiệm tiền sản không xâm lấn NIPT. Những người có trình độ học vấn cao hơn sẽ có mức sẵn sàng chi trả cho sàng lọc trước sinh hội chứng Down cao hơn những người có trình độ học vấn thấp. Những PNMT không phải công nhẩn và nông dân có mức sẵn sàng chi trả cho sàng lọc trước sinh hội chứng Down cao hơn PNMT ở nhóm công nhân, nông dân. Độ tuổi càng cao thì mức độ sẵn sàng chi trả cho sàng lọc trước sinh hội chứng Down càng tăng. Đây là những số liệu quan trong để các nhà hoach đinh chính sách, ban lãnh đạo và các nhà quản lý bệnh viện xây dựng giá của dịch vụ xét nghiệm tiền sản không xâm lấn và triển khai tuyên truyền những hiệu quả vượt trội của biện pháp xét nghiệm tiền sản không xâm lấn.

\section{TÀI LIỆU THAM KHẢO}

1. L.Venkatachalam, The contingent valuation method: a review. Institute for Social and Economic Change, 2003.

2. XiuruiGuo, H., Xianqiang Mao, Jianjun Jin, Dongsheng Chen, Shuiyuan Cheng, Willingness to pay for renewable electricity: A contingent valuation study in Beijing, China. Energy Policy, 2014. 68: p. 340-347.

3. Thanh, N.H., H.V. Minh, and N.v. Hùng, Âp dụng phương pháp định giá ngẫu nhiên phụ thuộc nghiên cứu săn sàng chi trá cho xây dựng hệ thống xử lý nước thải tại một vùng nông thôn Việt Nam. Tạp chí Nghiên cứu y học, 2012. 79(2): p. 151-157.

4. Wang, K., et al., Analysis of residents' willingness to pay to reduce air pollution to improve children's health in community and hospital settings in Shanghai, China. Science of The Total Environment, 2015. 533: p. 283-289.

5. Pei-JungLin, et al., Willingness to Pay for Diagnostic Technologies: A Review of the Contingent Valuation Literature. Value in Health, 2013. 16(5): p. 797-805.

6. Ilona M. Kopits, et al., Willingness to Pay for Genetic Testing for Alzheimer's Disease: A Measure of Personal Utility. GENETIC TESTING AND MOLECULAR BIOMARKERS, 2011. 15: p. 871875.

7. E.J.Verweij, et al., Non-invasive prenatal screening for trisomy 21: What women want and are willing to pay. PEC Journal, 2013. 93(3): p. 641-645. 